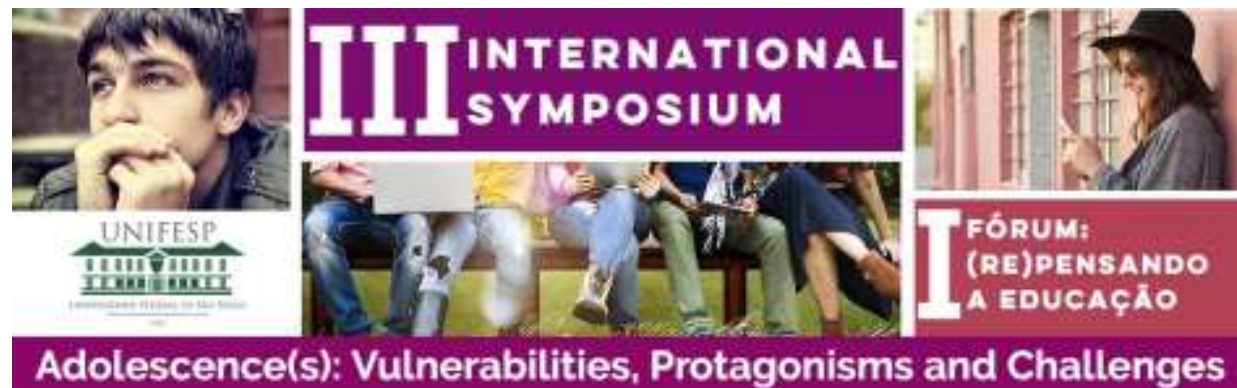

\title{
UNDERSTAND THE TERRITORIES UNDER THE GAZE OF TEENAGERS IN COLLECTIVES 'PROJOVEM': PHOTOVOICE CONTRIBUTIONS
}

\section{COMPREENDER OS TERRITÓRIOS SOB O OLHAR DE ADOLESCENTES EM COLETIVOS 'PROJOVEM': CONTRIBUIÇÕES DO PHOTOVOICE}

Letícia Felipe Domingues'; Ailton de Souza Aragão²; Rosimár Alves Querino ${ }^{3}$; Ana Carolina Graner Araújo Oliveira ${ }^{4}$; Maria Laura Cantore Ferro ${ }^{5}$; Fernanda Sousa Bastos de Moraes ${ }^{6}$; Letícia Carolina Buscaratti ${ }^{7}$; Maria Lopes Santos ${ }^{8}$; Gabriela Alves Martins Guimarães Lyrio Todo $^{9}$

Discente do curso de Psicologia. Universidade Federal do Triângulo Mineiro, Uberaba, MG E-mail: lehfdomingues@gmail.com

2. Professor Adjunto II do Departamento de Saúde Coletiva. Universidade Federal do Triângulo Mineiro, Uberaba, MG

E-mail: ailton.aragao@uftm.edu.br

3. Professor Associado do Departamento de Saúde Coletiva. Universidade Federal do Triângulo Mineiro, Uberaba, MG

E-mail: rosimar.querino@uftm.edu.br

4. Discente do curso de Psicologia. Universidade Federal do Triângulo Mineiro, Uberaba, MG E-mail: anacarolina-16@ hotmail.com

5. Discente do curso de Terapia Ocupacional. Universidade Federal do Triângulo Mineiro, Uberaba, MG

E-mail: marialauracferro@hotmail.com

6. Discente do curso de Educação Física. Universidade Federal do Triângulo Mineiro, Uberaba, MG

E-mail: nandasbm@gmail.com

7. Discente do curso de Terapia Ocupacional. Universidade Federal do Triângulo Mineiro, Uberaba, MG

E-mail: carolina@ hotmail.com

8. Discente do curso de Nutrição. Universidade Federal do Triângulo Mineiro, Uberaba, MG lopezinha2011@ hotmail.com

9. Discente do curso de Psicologia. Universidade Federal do Triângulo Mineiro, Uberaba, MG E-mail: gabrielaglyrio@gmail.com

*Projeto de Pesquisa 


\section{Como citar:}

DOMINGUES, Letícia Felipe et al. Understand the territories under the gaze of teenagers in collectives 'projovem': photovoice contributions. In: INTERNATIONAL SYMPOSIUM ADOLESCENCE(S) \& FÓRUM (RE)PENSANDO A EDUCAÇÃO, 3, 2017, São Paulo. Anais... São Paulo: Unifesp, 2017. p. 80-81. DOI: http://dx.doi.org/10.22388/2525-5894.2017.038

Resumo: A Política Nacional de Assistência Social preconiza que a Proteção Social Básica é a porta de entrada para o Sistema Único de Assistência Social, instituída nos Centros de Referência em Assistência Social, o qual efetiva o Programa Nacional de Inclusão de Jovens ao atender adolescentes de 15 a 17 anos em situação de vulnerabilidade, constituindo-se como espaço de trabalho socioeducativo. Objetivou-se compreender as percepções de adolescentes de Coletivos ProJovem sobre o modo como as drogas impactavam na dinâmica dos territórios. Estudo exploratório e descritivo, conduzido pelo photovoice, que incentivou o diálogo por meio da produção de imagens sobre o território e o tema em questão. As sessões de discussão das imagens, foram audiogravadas, transcritas na íntegra e analisadas na modalidade de discurso temática. Participaram do estudo 72 adolescentes de sete Coletivos ProJovem do município de Uberaba-MG, sendo aprovado pelo CEP-UFTM e a participação ocorreu após a assinatura do TCLE pelos pais e/ou responsáveis. Para além do tema das drogas, outras categoriais emergiram: faces das violências e fragilidades dos adolescentes. Há relações entre as vulnerabilidades no território identificadas pela deficiência, inexistência ou precariedade dos equipamentos e serviços públicos. Constatam os estigmas dos territórios em face das violências, seja pelas condições sociais seja pelo tráfico de drogas ou ambos. Dentre as faces da violência relataram, ainda, a doméstica e a intrafamiliar, a de gênero, a geracional. A violência gerada pelo tráfico foi entendida como forma de proteção e de manutenção da ordem na comunidade. Constatou-se um denso conhecimento dos/das adolescentes quanto a presença das violências, do tráfico e das drogas; e ainda, os desafios das instituições para lidar com os determinantes da questão social de modo dialógico e participativo, logo, que valorizem estratégias coletivas de empoderamento.

Palavras-chave: Metodologias. Direitos dos adolescentes. Adolescentes. Políticas Públicas. Vulnerabilidades. 